\section{ATMOSPHERIC SCIENCE Methane mystery}

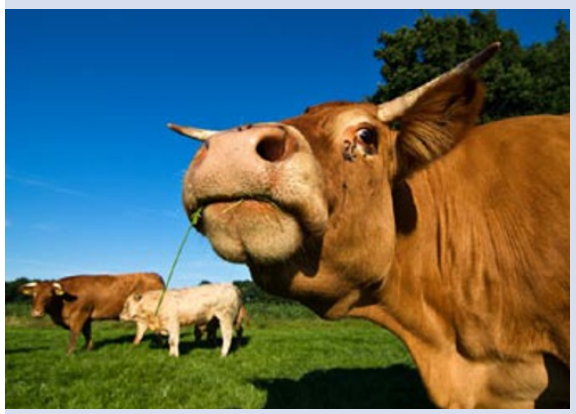

Geophys. Res. Lett. 35, L22805 (2008)

Atmospheric levels of the potent greenhouse gas methane rose sharply in early 2007 , having remained largely stable over the past decade. Methane is released from wetlands and wildfires as well as from human activities, such as fossil fuel use and farming, but is destroyed in the atmosphere when it reacts with a compound known as the hydroxyl radical.

Now Matthew Rigby of the Massachusetts Institute of Technology and colleagues have examined the change in global emissions of methane over a ten year period. They retrieved atmospheric measurements of methane and other chemical compounds from two monitoring networks with a total of 12 worldwide locations. Methane levels have risen simultaneously across all global sites since early 2007 . The team propose that the increase may have coincided with a slight decline in levels of the hydroxyl radical, but the changes in hydroxyl chemistry alone were insufficient to explain the entire methane rise.

By combining the data with numerical simulations from an atmospheric transport and chemistry model, they were able to attribute the methane spike to a worldwide rise in emissions between 2006 and 2007, the bulk of which originated in the Northern Hemisphere. The exact source of the extra methane, however, remains a mystery.

\section{Alicia Newton}

concentrations - 200 microlitres per litre above ambient levels — between 1996 and 2005. During this time, the forest floor accumulated an extra 30 grams of carbon per square metre per year. This build up of soil carbon could not be attributed to a decrease in the decomposition of organic matter and was probably the result of increased litterfall.

Although this represents a noteworthy increase in forest carbon storage, it is still small relative to human emissions, say the authors. However, with the first generation of FACE facilities set to close, the sustainability of this carbon sink will remain a mystery for a long time to come.

Anna Armstrong

\section{CRYOSPHERE}

\section{Thinning out}

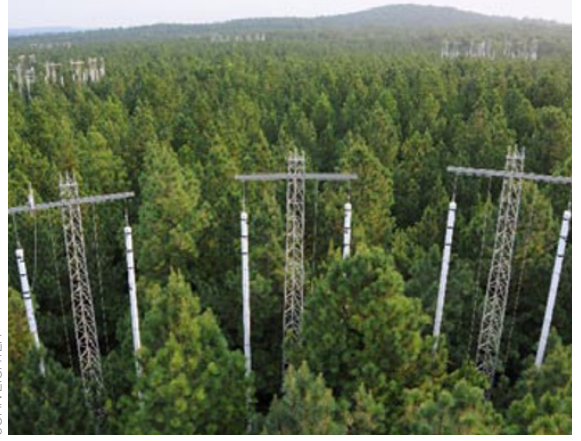

Geophys. Res. Lett. 35, L22503 (2008)

High elevation glaciers in the Himalayas release meltwater into the Indus, Ganges and Brahmaputra Rivers, contributing up to half of their total river flow. A new study suggests that these glaciers may be thinning, endangering water resources in one of the most populous regions of the world.

Natalie Kehrwald of Ohio State University and colleagues collected ice cores from the summit of Naimona'nyi Glacier in Tibet. The team measured the level of

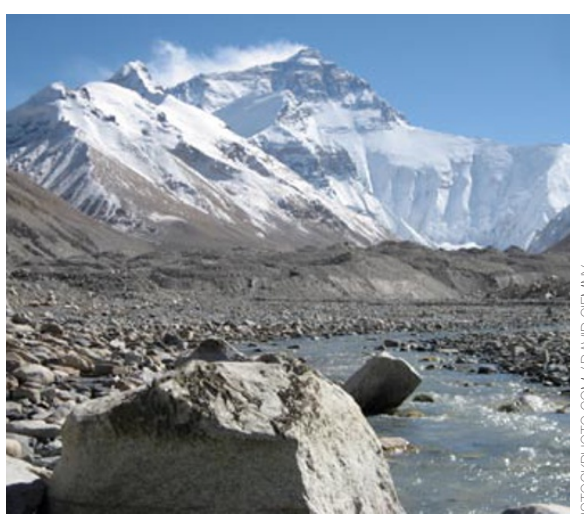

beta radioactivity and the concentration of two radioactive isotopes, chlorine-36 and hydrogen-3, in the ice. These isotopes are common signatures of nuclear weapons testing in the 1950s and 1960s. The notable absence of any radioactive signal in the cores, together with negligible concentrations of radioactive isotopes, indicates that the glacier has had no ice deposited since the 1950s; lead dating confirmed this finding. The authors suggest that increased ice melt resulting from recent warming may be responsible.

Current estimates of the impact of Himalayan glacial retreat on water resources have failed to account for high elevation glacial thinning. If Naimonanyi is characteristic of other glaciers in the region, meltwater supply is likely to shrink much faster than currently predicted, with considerable negative consequences for up to half a billion people.

\section{Anna Armstrong}

\section{ANTHROPOGENIC CHANGE}

\section{Double trouble}

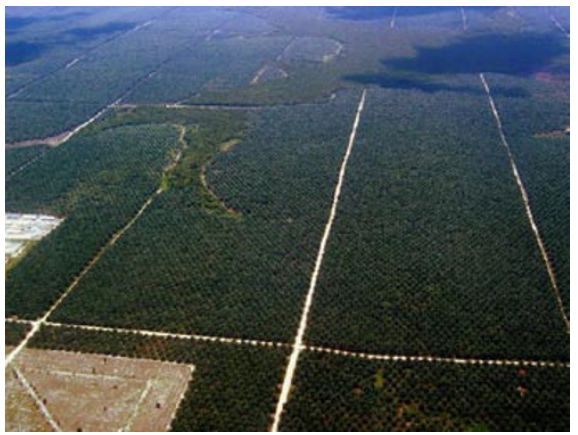

Conservation Biol. doi:10.1111/ j.1523-1739.2008.01096.x (2008)

Replacing tropical rainforests with oil palm plantations threatens biodiversity and efforts to reduce greenhouse gas emissions, report scientists. One of a number of biofuel crops touted as a sustainable, environmentally friendly energy source, palm oil now covers some 13 million hectares of land surface worldwide, mostly in Southeast Asia. 
An international team of researchers, led by Finn Danielsen of Denmark's Nordic Agency for Development and Ecology, has carried out the most comprehensive analysis yet of the impact of oil palm plantations on tropical forests. They estimate it would take 75 to 93 years for the carbon saved through the use of biofuels to compensate for the carbon lost through clearing tropical rainforest. This payback time would increase to more than 600 years if the original habitat was peatland, and would decrease to just 10 years on degraded grassland, they say. Based on a meta-analysis of faunal data and a comparative field study of flora on forested and converted land in Indonesia, they also show that plantations support species-poor communities compared to forests, and that the most abundant species in converted lands are generalists of low conservation value.

The authors call for global standards to assess the sustainability of biofuel crops.

Olive Heffernan

PALEOCLIMATE

\section{Calcium connection}

Science 322, 1671-1674 (2008)

Scientists have uncovered evidence that oceanic calcium concentrations have fluctuated widely over the past 28 million years. The concentration of marine calcium has important implications for ocean alkalinity and for the absorption and storage of atmospheric carbon dioxide in the deep sea.

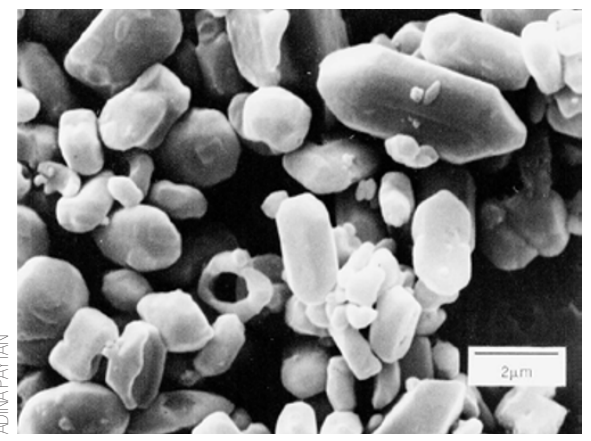

Previous efforts to understand the calcium cycle based on ratios of different isotopes or forms of calcium in marine carbonates, have been hampered by changes in environmental conditions in the ocean that also affect the ratios. To avoid this artefact, Elizabeth Griffith of Stanford University, California, and colleagues turned to tiny crystals of barite, a sulphur-based mineral formed in sea water. They measured the ratio of calcium isotopes trapped in the crystals, which is believed to be unaffected by environmental variability. The group found that the amount of dissolved calcium in the oceans - as well as the isotopic composition of that calcium - has varied dramatically during the past 28 million years.

The most pronounced change occurred 13 million years ago, as the climate cooled and Antarctic ice sheets began to increase. The discovery that marine calcium concentrations have been unstable over long geological periods represents a considerable advance in the understanding of global biochemical cycles, which form a crucial component of the climate system.

Alicia Newton

\section{BIODIVERSITY AND ECOLOGY}

\section{Bad news for bears}

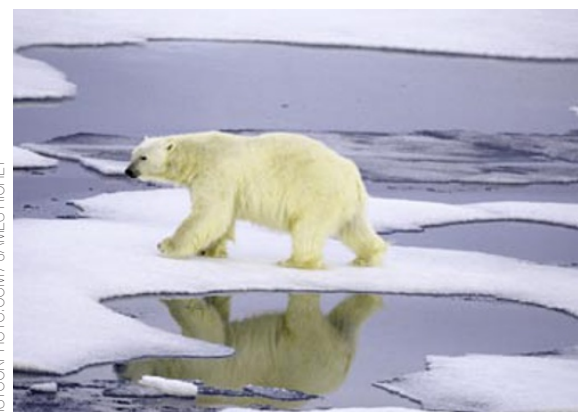

Polar Biol. doi:10.1007/s00300-008-0530-0 (2008)

Polar bears in the Beaufort Sea region of the Arctic are finding it increasingly difficult to find food during springtime, suggests a new study.

Seth Cherry of the University of Alberta, Canada, and colleagues located polar bears by helicopter and anesthetized them using a dart gun before taking blood samples to determine their serum urea to serum creatinine $(\mathrm{U} / \mathrm{C})$ ratios. $\mathrm{U} / \mathrm{C}$ values, which are low when bears are in a physiological fasting state, were obtained for 436 individuals during April and May of 1985-1986 and 2005-2006. Of the bears sampled by Cherry's team, the numbers fasting were 9.6 per cent in 1985 and 10.5 per cent in 1986, increasing to 21.4 per cent in 2005 and 29.3 per cent in 2006. Polar bears from all sex, age and reproductive classes were more likely to be found fasting in 2005-2006 than in 1985-1986. During all years of the study, adult males involved in breeding comprised a high proportion of the bears with low U/C levels.

Satellite data over this period shows significant declines in the extent of Arctic sea ice, a change that may affect the bears' ability to hunt and catch seals during the spring feeding period.

Olive Heffernan

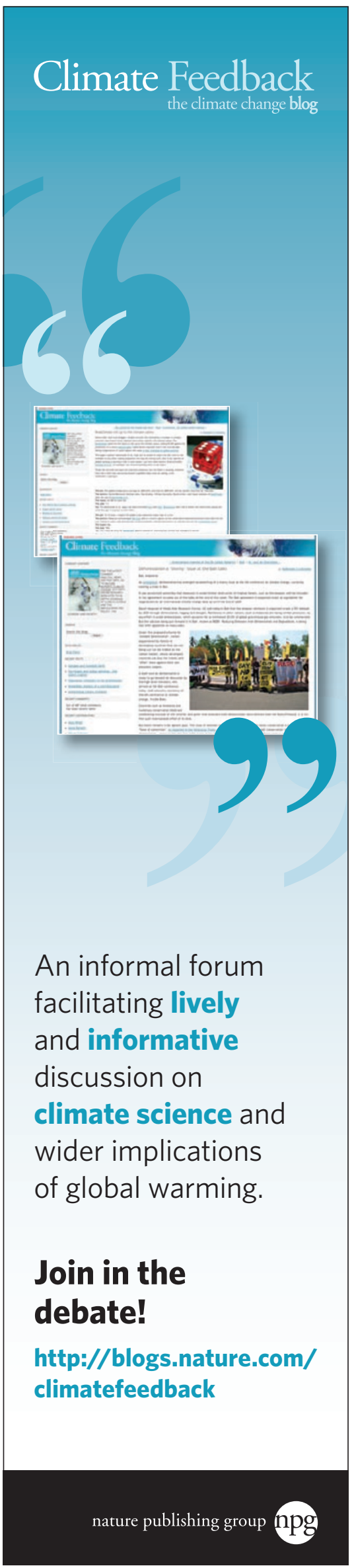

